\title{
Pengaruh Penerapan Aplikasi Sayang ke Buah Hati (SEHATI) terhadap Pengetahuan Ibu dan Aktivitas Fisik pada Anak Sekolah Dasar
}

\author{
Nurul Auliya Kamila, ${ }^{1}$ Hadi Susiarno, ${ }^{2}$ Dida Akhmad Gurnida, ${ }^{3}$ \\ Irvan Afriandi, ${ }^{4}$ Herry Garna, ${ }^{3}$ Tono Djuwantono ${ }^{2}$ \\ ${ }^{1}$ Fakultas Kedokteran, Universitas Padjadjaran, Bandung, \\ ${ }^{2}$ Departemen Obstetri dan Ginekologi, ${ }^{3}$ Departemen Ilmu Kesehatan Anak, \\ ${ }^{4}$ Departemen Ilmu Kesehatan Masyarakat, Fakultas Kedokteran, Universitas Padjadjaran, Bandung
}

\begin{abstract}
Abstrak
Aktivitas fisik yang tidak cukup adalah 1 dari 10 faktor risiko utama kematian di seluruh dunia karena merupakan faktor risiko utama penyakit tidak menular seperti penyakit kardiovaskular, kanker, dan diabetes melitus. Aplikasi Sayang ke Buah Hati (SEHATI) adalah media informatif yang merupakan panduan bagi ibu dalam meningkatkan pengetahuan dan panduan tentang aktivitas fisik yang benar pada anak usia sekolah dasar yang dikemas dalam bentuk animasi bergerak, warna menarik, dan sistem pengingat waktu/reminder. Dilakukan penelitian quasi experiment dengan pretest-postest with control group design untuk menganalisis pengaruh aplikasi SEHATI terhadap pengetahuan ibu dan aktivitas fisik pada anak usia sekolah dasar selama Januari 2017. Subjek penelitian ibu yang memiliki anak usia sekolah dasar berusia 8-12 tahun di SDIT Uchuwwatul Islam Kota Bandung sebanyak 60 orang yang terbagi dalam 2 kelompok, yaitu kelompok intervensi menggunakan aplikasi SEHATI dan kelompok kontrol tidak diterapkan. Pengambilan sampel berdasar atas teknik proportionate stratified random sampling. Pengujian statistik menggunakan uji chi-square dengan kemaknaan $\mathrm{p}<0,05$. Hasil penelitian menunjukkan tidak terdapat perbedaan karakteristik responden pada kedua kelompok meliputi usia, pendidikan, pekerjaan, dan paritas. Karakteristik ibu pada kelompok intervensi dan kontrol didominasi oleh usia 30-39 tahun, berpendidikan menengah (SMA, SMP), tidak bekerja, dan paritas multipara. Persentase peningkatan skor pengetahuan pada kelompok intervensi lebih baik daripada kelompok kontrol ( $25 \%$ vs $19 \%$; $\mathrm{p}=0,001)$. Skor aktivitas fisik anak peningkatannya lebih baik pada kelompok intervensi ( $78 \%$ vs $61 \%$; $\mathrm{p}=0,602$ ). Simpulan, aplikasi SEHATI berpengaruh dalam meningkatkan pengetahuan ibu dan aktivitas fisik anak usia sekolah dasar.
\end{abstract}

Kata kunci: Aktivitas fisik, anak sekolah dasar, Aplikasi Sayang ke Buah Hati (SEHATI), pengetahuan

\section{The Effect of Affectionate to Baby (SEHATI) Application on Mother's Knowledge and Physical Activity in Primary School Age Children}

\begin{abstract}
The lack of physical activity is one of the 10 major risk factors of death in the world, it is major risk factors for non-communicable diseases such as cardiovascular diseases, cancer, and diabetes mellitus. Affectionate to Baby (SEHATI) application is informative media which is a guide for mothers in improving the knowledge and guidance on the correct physical activity in children of primary school age are packaged in the form of moving animations, exciting colors, and the system time reminder. A quasi experiment with pretest-posttest control group design was conducted to analyze the effect of the SEHATI application toward knowledge mother and physical activity in school age children during January 2017. The subjects of this research were 60 mothers who have primary school age children as well as those aged 8-12 years in SDIT Uchuwwatul Islam Bandung. The respondent were divided into two groups the intervention group and the control group. The sampling based on proportionate stratified random sampling. The statistical test using chi-square test with the significance of test results is determined by the value of $\mathrm{p}<0.05$. The results showed there were no differences in the characteristics of respondents in both groups, including age, education, occupation, and parity. Characteristics of mothers in the intervention and the control group was dominated by the age of 30-39, secondary education (high school, junior high school), not working, and parity multiparous. The percentage increase of knowledge score in the intervention group was better than the control group 25\% vs $19 \%, p=0.001$. Percentage increase of the children's physical activity score in the intervention group was better than the control group $78 \%$ vs $61 \%, p=0.602$. Conclusion, SEHATI application is influential in increasing the knowledge of the mother and the physical activity of children of primary school age.
\end{abstract}

Key words: Affectionate to baby (SEHATI) application, knowledge, physical activity, primary school children

Korespondensi: Nurul Auliya Kamila. Fakultas Kedokteran, Universitas Padjadjaran, Jln. Eijkman No. 38, Bandung, Jawa Barat, Indonesia. HP: +6281703830022. E-mail: mila_yk2007@yahoo.com 


\section{Pendahuluan}

Aktivitas fisik yang tidak cukup adalah satu dari 10 faktor risiko utama kematian di seluruh dunia dan merupakan faktor risiko yang utama penyakit tidak menular atau non-communicable disease/NCD seperti penyakit kardiovaskular, kanker, dan diabetes melitus. ${ }^{1}$ World Health Organization (WHO) memperkirakan bahwa 1,9 juta kematian di seluruh dunia disebabkan oleh fisik yang tidak aktif dan sekurang-kurangnya 2,6 juta meninggal karena kegemukan dan obesitas. ${ }^{2}$ Berdasar atas data Riset Kesehatan Dasar tahun 2013 atau Riskesdas 2013, di Indonesia secara nasional masalah kegemukan pada anak usia $5^{-12}$ tahun masih tinggi, yaitu $18,8 \%$ yang terdiri atas gemuk 10,8\% dan sangat gemuk (obesitas) 8,8\% dan di Jawa Barat mencapai $19 \%{ }^{3}$

Obesitas adalah keadaan akumulasi lemak abnormal atau berlebihan di dalam tubuh yang dapat menimbulkan beberapa risiko kesehatan individu. ${ }^{4,5}$ Literatur memperlihatkan pada anak dan remaja dengan indeks massa tubuh/body mass index (BMI) 85-94 persentil dikategorikan ke dalam golongan overweight dan BMI $>95$ dalam obesitas..$^{4,6}$ Anak obesitas adalah salah satu tantangan kesehatan masyarakat paling serius pada abad ke-21 dan terus memengaruhi banyak negara berpenghasilan rendah dan menengah, khsususnya perkotaan. ${ }^{7}$ Diet dan aktivitas fisik merupakan yang faktor penting dalam menjaga rentang BMI yang sehat. ${ }^{8}$

Anak dengan kelebihan berat badan dan juga obesitas akan cenderung tetap obesitas pada masa dewasa dan akan lebih mungkin berisiko mengalami penyakit yang tidak menular seperti diabetes melitus dan penyakit kardiovaskular. ${ }^{9}$ Pendidikan kesehatan untuk aktivitas fisik adalah strategi promosi kesehatan untuk meningkatkan kesehatan individu dan juga populasi, bahkan beberapa tinjauan sistematik menyoroti beberapa manfaat aktivitas fisik pada anak yang sehat. ${ }^{10}$ Aktivitas fisik memiliki manfaat kesehatan yang signifikan dan memberikan kontribusi untuk mencegah dan mengatasi NCD. ${ }^{11,12}$ Secara global, 1 dari 4 orang tidak cukup aktif, lebih dari $80 \%$ populasi remaja di dunia adalah kurang aktif secara fisik. ${ }^{1}$ Kemajuan teknologi membuat anak semakin pasif dan memiliki gaya hidup yang santai (sedentary lifestyle) ${ }^{13}$ karena anak lebih memilih menghabiskan waktu di depan televisi atau bermain gim. ${ }^{14}$

World Health Organization atau WHO juga menyatakan keadaan yang sama pentingnya pada tahun 2013 mengesahkan rencana global (Global NCD Action Plan 2013-202O) yang mencakup serangkaian tindakan negara anggota untuk mempromosikan diet sehat dan aktivitas fisik. Negara para anggota WHO telah sepakat untuk mengurangi aktivitas fisik tidak cukup sampai 10\% pada tahun 2025. ${ }^{15}$

Dalam Riskesdas 2013 aktivitas fisik tiap hari memiliki urutan 4 terendah dalam 10 indikator PHBS, yaitu 52,8\%. ${ }^{3}$ Anak sekolah dasar (6-12 tahun) pada masa ini mengalami pertumbuhan dan memiliki karakteristik mulai ingin mencoba untuk mengembangkan kemandirian. Restoran makanan junk food atau cepat saji yang semakin marak di kota-kota besar disertai aktivitas yang minimal dalam keseharian memengaruhi gaya hidup anak terutama di perkotaan. ${ }^{8}$

Aktivitas fisik yang rendah di kalangan anak sekolah dasar disebabkan oleh beberapa faktor. Faktor-faktor tersebut termasuk tidak terdapat sarana aktivitas fisik yang memadai di sekolah. Sekolah-sekolah lebih banyak mengutamakan sarana pembelajaran yang mendukung aspek kognitif para siswa dan kurang memperhatikan perkembangan aspek fisik anak. Di samping itu, kurikulum sekolah yang kurang memfasilitasi perkembangan terhadap aspek fisik anak juga turut menjadi faktor penyebab aktivitas fisik yang rendah di kalangan siswa. Sebesar 60\% sekolah hanya menyediakan waktu dua jam tiap minggu untuk kegiatan olahraga. ${ }^{8,16,17}$

Di Indonesia sebanyak $48,2 \%$ penduduk yang berusia $>10$ tahun kurang melakukan aktivitas fisik.${ }^{18}$ Keluarga merupakan sumber penting untuk dukungan sosial bagi anak di dalam melakukan aktivitas fisik. Penelitian yang dilakukan oleh Shaw dan Shaw $^{7}$ telah memperlihatkan bahwa orangtua dapat memengaruhi aktivitas fisik anak mereka, baik itu secara langsung maupun tidak langsung. Orangtua yang mengetahui pentingnya aktivitas fisik cenderung mempunyai anak lebih aktif dan orangtua aktif secara fisik cenderung lebih terlibat dalam kegiatan fisik anak mereka.

Fisik yang tidak aktif diidentifikasikan sebagai faktor risiko utama keempat untuk kematian global. ${ }^{19}$ Menurut rekomendasi WHO anak usia 5-17 tahun harus melaksanakan aktivitas fisik setidaknya 60 menit per hari.9,20

Mahasiswa dari Program Studi Magister Ilmu Kebidanan, Universitas Padjadjaran yang terdiri atas 4 mahasiswa melaksanakan pengembangan prototipe sistem promosi kesehatan terhadap anak dengan memanfaatkan aplikasi di dalam smartphone. Pada prototipe itu, materi yang 
diangkat adalah empat cakupan perilaku hidup bersih dan sehat atau PHBS terendah berdasar atas Riskesdas 2013, yaitu mengonsumsi aneka ragam makanan berbasis pedoman umum gizi seimbang, melakukan aktivitas fisik, mencuci tangan memakai sabun, serta menggosok gigi. Aplikasi tersebut diberi nama Sayang ke Buah Hati atau SEHATI yang mudah dioperasikan oleh orang awam sehingga diharapkan dapat memudahkan ibu-ibu meningkatkan kesadaran, kebiasaan positif, dan pengetahuan akan upaya promotif serta preventif penyakit pada anak. Diharapkan dengan melaksanakan aktivitas fisik maka morbiditas anak di Indonesia mengalami penurunan dan terciptanya kesejahteraan pada anak. Tujuan penelitian ini adalah menganalisis perbedaan pengetahuan ibu tentang aktivitas fisik pada anak sekolah dasar sebelum dengan sesudah penerapan aplikasi SEHATI dan menganalisis perbedaan aktivitas fisik anak sekolah dasar sebelum dengan sesudah penerapan aplikasi SEHATI.

\section{Metode}

Penelitian ini menggunakan rancangan quasi experiment dengan pretest-posttest with control group design. Subjek penelitian ibu yang memiliki anak usia sekolah dasar yang berusia 8-12 tahun di SDIT Uchuwwatul Islam Kota Bandung sebanyak 60 orang yang terbagi ke dalam dua kelompok, yaitu kelompok intervensi dengan diterapkannya aplikasi SEHATI dan kelompok kontrol tidak diterapkan selama Januari 2017. Pengambilan sampel itu berdasar atas teknik probability sampling dengan cara proportionate stratified random sampling. Pengujian statistik menggunakan uji chi-square dengan kemaknaan hasil uji ditentukan berdasar atas nilai $\mathrm{p}<0,05$.

Kuesioner pengetahuan mengacu pada Global Recommendation Physical Activity for Health dari WHO. Skor pengetahuan dikategorikan dalam dua kriteria, yaitu jika hasil skor penilaian $\leq 50$ : pengetahuan dikatakan kurang, sedangkan bilamana hasil skor penilaian $\geq 50$ : pengetahuan dikatakan baik. Kuesioner aktivitas fisik mengacu pada Physical Activity Questioner for Older Children (PAQ-C). PAQ-C merupakan instrumen aktivitas fisik recall selama 7 hari terakhir. Total skor PAQ-C dinilai rendah jika skor PAQ-C 9-2, sedang 22-33, dan tinggi 34-45.

Persetujuan etik telah dikeluarkan Komisi Etik Penelitian Kesehatan, Fakultas Kedokteran, Unpad, Bandung (Nomor 1/UN6.C1.3.2/KEPK/ PN/2017).

\section{Hasil}

Berdasar atas Tabel 1 karakteristik responden yang meliputi usia, pendidikan, pekerjaan, dan paritas pada kedua kelompok penelitian tidak bermakna $(p>0,05)$. Dengan demikian, dapat

Tabel 1 Karakteristik Responden pada Kedua Kelompok Penelitian

\begin{tabular}{|c|c|c|c|}
\hline \multirow{2}{*}{ Karakteristik } & \multicolumn{2}{|c|}{ Kelompok } & \multirow{2}{*}{$\mathbf{p}^{*}$} \\
\hline & Intervensi $(\mathbf{n}=\mathbf{3 0})$ & Kontrol $(n=30)$ & \\
\hline \multicolumn{4}{|l|}{ Usia (tahun) } \\
\hline$<30$ & 5 & 4 & \multirow{4}{*}{0,845} \\
\hline $30-39$ & 13 & 12 & \\
\hline $40-49$ & 10 & 10 & \\
\hline$\geq 50$ & 2 & 4 & \\
\hline \multicolumn{4}{|l|}{ Pendidikan } \\
\hline Dasar (SD) & 3 & 1 & \multirow{3}{*}{0,509} \\
\hline Menengah (SMP, SMA) & 26 & 27 & \\
\hline Tinggi (PT) & 1 & 2 & \\
\hline \multicolumn{4}{|l|}{ Pekerjaan } \\
\hline Tidak bekerja & 23 & 24 & \multirow{2}{*}{0,754} \\
\hline Bekerja & 7 & 6 & \\
\hline \multicolumn{4}{|l|}{ Paritas } \\
\hline Primipara & 3 & 3 & \multirow{2}{*}{1,000} \\
\hline Multipara & 27 & 27 & \\
\hline
\end{tabular}

Keterangan: *berdasar atas uji chi-square 
disimpulkan bahwa kedua kelompok responden memiliki karakteristik yang homogen sehingga layak untuk diperbandingkan.

Berdasar atas Tabel 2 terdapat perbedaan skor pengetahuan dan keterampilan antara kelompok intervensi dan kontrol setelah tes atau postes. Peningkatan skor pengetahuan pada kelompok intervensi $6 \%$ lebih tinggi daripada kelompok kontrol. Nilai rata-rata, median, dan rentang pada kelompok intervensi lebih tinggi dibanding dengan kelompok kontrol.

Pada Tabel 3 skor aktivitas fisik pada kelompok intervensi dan kontrol mengalami peningkatan nilai rata-rata setelah penelitian. Peningkatan nilai rata-rata pada kelompok intervensi sebesar 6,5 dan pada kelompok kontrol 3,3. Peningkatan skor pengetahuan pada kelompok intervensi $17 \%$ lebih tinggi daripada kelompok kontrol. Skor aktivitas fisik pretes pada kedua kelompok tidak berbeda $(p>0,05)$ dengan hasil uji Mann-Whitney berarti kedua kelompok dapat dibandingkan. Pada postes skor aktivitas fisik anak berdasar atas uji independen $t$ didapatkan nilai $p>0,05$, hal ini menunjukkan tidak terdapat perbedaan skor aktivitas fisik anak setelah diberikan aplikasi SEHATI antara kelompok intervensi dan kontrol.

\section{Pembahasan}

Pengetahuan ibu tentang aktivitas fisik anak harus diberikan kepada masyarakat luas tidak terbatas pada kelompok lingkungan perkotaan, tetapi juga di pedesaan sudah sepatutnyalah mendapatkan informasi yang jelas dan akurat mengenai hal ini. Diharapkan dengan mengetahui informasi aktivitas fisik pada anak maka orangtua dapat menyadari bahwa aktivitas fisik pada anak ini penting.

Berdasar atas hasil uji statistik pada Tabel 2 diperoleh hasil bahwa skor pengetahuan pretes pada kedua kelompok tidak memiliki perbedaan yang bermakna $(p>0,05)$ artinya kondisi awal pengetahuan pada kedua kelompok itu adalah sama. Hampir semua responden pada kelompok intervensi atau kelompok kontrol belum memiliki pengetahuan yang baik tentang aktivitas fisik pada anak-anak usia sekolah dasar. Keadaan ini sesuai dengan hasil penelitian di Semarang yang dilakukan oleh Zahro ${ }^{21}$ yang menyatakan bahwa pengetahuan dan praktik ibu yang kurang tentang aktivitas fisik pada anak, serta sikap ibu yang tidak mendukung aktivitas fisik pada anak berisiko kejadian obesitas pada anak. Hal ini berbeda dengan hasil skor pengetahuan postes, pada kelompok intervensi yang menggunakan aplikasi SEHATI menunjukkan perbedaan bermakna $(\mathrm{p}=0,024)$ sehingga dapat disimpulkan aplikasi SEHATI meningkatkan pengetahuan ibu.

Hasil penelitian ini sesuai dengan penelitian Sharma dan Nagar $^{22}$ yang menyatakan bahwa pemberianinformasipadaibuakan meningkatkan pengetahuan ibu tentang aktivitas fisik pada anak. Hasil penelitian ini juga sejalan dengan penelitian oleh Penny dkk. ${ }^{23}$ yang menunjukkan bahwa pemberian informasi memiliki relevansi dengan peningkatan pengetahuan. Pengetahuan dapat memengaruhi pola pikir dan pemahaman informasi yang diterimanya. Sesuai dengan teori

Tabel 2 Perbandingan Skor Pengetahuan Ibu Sebelum dengan Setelah Intervensi

\begin{tabular}{|c|c|c|c|}
\hline \multirow{2}{*}{ Variabel (Skala 10o) } & \multicolumn{2}{|c|}{ Kelompok } & \multirow{2}{*}{$\mathbf{p}^{*}$} \\
\hline & Intervensi $(n=30)$ & Kontrol $(n=30)$ & \\
\hline \multicolumn{4}{|l|}{ Skor pengetahuan } \\
\hline \multicolumn{4}{|l|}{ Pretes } \\
\hline Rata-rata (SD) & $44,7(13,3)$ & $48,0(15,3)$ & \multirow{3}{*}{0,698} \\
\hline Median & 45,0 & 45,0 & \\
\hline Rentang & $20-75$ & $15-90$ & \\
\hline \multicolumn{4}{|l|}{ Postes } \\
\hline Rata-rata (SD) & $61,7(15,9)$ & $52,0(16,4)$ & \multirow{3}{*}{0,024} \\
\hline Median & 62,5 & 45,0 & \\
\hline Rentang & $25-85$ & $15-90$ & \\
\hline \multicolumn{4}{|l|}{ Perbandingan } \\
\hline Pretes vs postes** & $\mathrm{p}=\mathrm{O}, \mathrm{oO} 1$ & $\mathrm{p}=0,009$ & \multirow{2}{*}{0,001} \\
\hline \% naik (mean) & $25 \%$ & $19 \%$ & \\
\hline
\end{tabular}

Keterangan: *uji Mann-Whitney, ${ }^{* *}$ uji independen t 
Tabel 3 Perbandingan Aktivitas Fisik Anak Sebelum dengan Setelah Intervensi

\begin{tabular}{|c|c|c|c|}
\hline \multirow{2}{*}{ Variabel (Skala 10o) } & \multicolumn{2}{|c|}{$\begin{array}{c}\text { Kelompok } \\
\end{array}$} & \multirow{2}{*}{$\mathbf{p}^{*}$} \\
\hline & Intervensi $(\mathbf{n}=\mathbf{3 0})$ & Kontrol $(n=30)$ & \\
\hline \multicolumn{4}{|l|}{ Skor aktivitas fisik } \\
\hline Pretes & & & \\
\hline Rata-rata (SD) & $35,4(16,9)$ & $435,4(18,8)$ & \multirow{3}{*}{0,953} \\
\hline Median & 33,3 & 27,8 & \\
\hline Rentang & $11,1-72,2$ & $8,3-86,1$ & \\
\hline \multicolumn{4}{|l|}{ Postes } \\
\hline Rata-rata (SD) & $41,9(16,4)$ & $38,7(18,4)$ & \multirow{3}{*}{0,475} \\
\hline Median & 41,7 & 34,7 & \\
\hline Rentang & $19,4-72,2$ & $13,9-91,7$ & \\
\hline \multicolumn{4}{|l|}{ Perbandingan } \\
\hline Pretes vs postes** & $\mathrm{p}=0,004$ & $\mathrm{p}=0,019$ & \multirow{2}{*}{0,602} \\
\hline \% naik (mean) & $78 \%$ & $61 \%$ & \\
\hline
\end{tabular}

Keterangan: *uji Mann-Whitney, ${ }^{* *}$ uji independen t

yang dikemukakan oleh Notoatmodjo ${ }^{24}$ bahwa aspek pengetahuan merupakan domain yang sangat penting untuk pembentukan perilaku seseorang, semakin tinggi tingkat pengetahuan seseorang akan dapat memengaruhi pola pikir dan sikap terhadap sesuatu.

Pengetahuan yang baik tentang aktivitas fisik dapat dipengaruhi oleh media yang dipergunakan pada waktu pemberian informasi tersebut. Media pendidikan kesehatan berfungsi mengerahkan indera sebanyak-banyaknya pada suatu objek sehingga akan mempermudah persepsi. Media pendidikan akan membuat seseorang dapat lebih mengerti informasi atau materi yang dianggap rumit menjadi lebih mudah. ${ }^{24}$

Penggunaan media tersebut akan membantu memperjelas informasi yang disampaikan karena akan lebih menarik, lebih interaktif, serta dapat mengatasi batasan ruang, waktu, dan juga indera manusia. Agar informasi yang disampaikan dapat lebih jelas dan mudah dipahami sesuai dengan tujuan yang akan dicapai maka informasi tersebut harus dikemas yang sesuai dengan karakteristik setiap media yang dipergunakan. Penggunaan media dapat meningkatkan pengetahuan yang keberhasilannya akan ditentukan oleh efektivitas media dan efektivitas penggunaan media tersebut sangat ditentukan oleh banyaknya indera yang digunakan. ${ }^{25}$

Media audiovisual memberikan stimulus pada pendengaran dan penglihatan sehingga hasil yang diperoleh maksimal. Hasil tersebut dapat tercapai karena pancaindera yang paling banyak menyalurkan pengetahuan ke otak adalah mata ( $\pm 75-87 \%)$, sedangkan $13 \%$ sampai $25 \%$ pengetahuan diperoleh atau disalurkan melalui indera yang lain. Media audiovisual mempunyai kelebihan utama antara lain dapat memberikan gambaran yang lebih nyata serta meningkatkan retensi memori karena lebih menarik dan juga mudah diingat. ${ }^{26}$ Media audiovisual juga memiliki kelebihan yang tidak ada pada media lainnya dengan mengikutsertakan seluruh pancaindera, langsung bertatap muka, dan akan lebih menarik karena ada suara dan gambar yang bergerak. Penggunaan media audiovisual itu menjadi lebih menarik perhatian bagi responden sehingga akan membangkitkan antusiasme untuk mendapatkan informasi dan juga lebih mudah diterima. ${ }^{25}$

AplikasiSEHATImerupakan media pemberian informasi berbentuk audiovisual yang dilengkapi dengan animasi untuk menarik minat orangtua dalam memberikan edukasi kesehatan pada anak mereka. Animasi sebagai media pembelajaran memiliki kemampuan untuk memaparkan suatu yang rumit atau kompleks serta sulit dijelaskan dengan hanya gambar atau kata-kata. Berdasar atas hasil penelitian yang dilakukan oleh O' day $^{27}$ dinyatakan bahwa penggunaan animasi memiliki kelebihan dibanding dengan media lain, yaitu informasi yang didapatkan dari animasi pada memori jangka panjang. Pernyataan yang sama juga oleh Balazinski dan Pryzbylo ${ }^{28}$ menyatakan bahwa penggunaan media animasi itu dalam pembelajaran dapat mengurangi waktu proses pembelajaran serta hasil tes meningkat sebesar $15 \%$. Sejalan dengan penelitian Aksoy ${ }^{29}$ yang menyatakan bahwa metode animasi lebih efektif 
daripada metode pengajaran secara tradisional dalam menaikkan hasil belajar siswa.

Penggunaan animasi pada aplikasi SEHATI lebih meningkatkan pengetahuan ibu tentang aktivitas fisik anak usia sekolah dasar. Berdasar atas hasil uji statistik pada Tabel 2 menunjukkan bahwa aplikasi SEHATI itu lebih meningkatkan pengetahuan bila dibanding dengan kelompok yang tidak diberikan aplikasi SEHATI. Saat ini ponsel tidak hanya berfungsi sebagai sarana telekomunikasi, akan tetapi telah beralih menjadi gadget (gawai) yang mampu melakukan banyak hal. Ponsel jenis ini sekarang lebih dikenal dengan istilah smartphone dapat dipergunakan untuk membantu kegiatan medis seperti halnya penetapan diagnosis dan terapi. Dari berbagai bentuk teknologi informasi dan telekomunikasi, ponsel dianggap merupakan alat yang sangat cocok untuk memajukan pendidikan di daerah berkembang.

Berdasar atas hasil uji statistik pada Tabel 3 diperoleh hasil bahwa skor aktivitas fisik anak pretes pada kedua kelompok tidak mempunyai perbedaan bermakna ( $>>0,05)$ artinya kondisi awal aktivitas fisik pada kedua kelompok adalah sama. Setelah postes maka skor aktivitas anak tidak menunjukkan perbedaan yang bermakna ( $p>0,05)$, yaitu $\mathrm{p}=0,602$, sedangkan bila dilihat dari aktivitas fisik pada kelompok intervensi dibanding dengan kelompok kontrol terdapat perbedaan $(78 \%$ vs $61 \%)$. Pada penelitian ini penilaian skor aktivitas fisik pada anak dilakukan dengan kuesioner self report aktivitas fisik yang mengacu pada Physical Activity Questioner for Older Children (PAQ-C). ${ }^{29}$ Physical Activity Question for Children adalah instrumen aktivitas fisik recall selama 7 hari terakhir sehingga dapat terjadi kesalahan seperti anak lupa atau hanya memperkirakan aktivitas fisik yang telah mereka lakukan. Self report adalah yang paling sering digunakan untuk penilaian aktivitas fisik pada anak dan remaja karena biaya lebih rendah dan dapat dengan mudah digunakan pada populasi besar.

Aktivitas fisik penting untuk kesehatan fisik anak dan kesejahteraannya. Banyak faktor yang berkontribusi terhadap aktivitas fisik anak-anak dan lingkungan memegang peranan yang penting karena anak telah menghabiskan banyak waktu mereka di dalam dan sekitar lingkungan mereka. Meningkatkan proporsi anak dan remaja yang terlibat dalam aktivitas fisik secara teratur terus menjadi prioritas kesehatan yang global. Aktivitas fisik secara keseluruhan juga dapat dipengaruhi oleh lingkungan sekolah, masyarakat, keluarga, dan faktor lainnya. Anggota keluarga, terutama orangtua memainkan peran yang penting dalam perkembangan perilaku kesehatan anak-anak. ${ }^{29}$ Akan tetapi, bagaimana mekanisme pengaruh orangtua tersebut masih belum dapat dijelaskan. Pemahaman komprehensif tentang bagaimana orangtua memengaruhi perilaku aktivitas fisik anak-anak diperlukan untuk menginformasikan perkembangan aktivitas fisik yang efektif berbasis keluarga. ${ }^{29}$

Pada Tabel 3 skor aktivitas fisik berdasarkan uji independen $t$ diperoleh nilai $p>0,05$ pada kelompok intervensi dan kontrol. Keadaan ini menunjukkan tidak terdapat perbedaan skor aktivitas fisik anak setelah diberikan aplikasi SEHATI pada kelompok intervensi dan kontrol. Sampai saat ini sebagian besar penelitian yang mempunyai kaitan dengan aktivitas fisik anak sudah difokuskan pada pemodelan langsung. Penelitian sudah melaporkan korelasi yang positif antara tingkat aktivitas fisik orangtua dan anak mereka. Hal ini sesuai dengan hasil penelitian oleh Gustafson dan Rhodes ${ }^{30}$ yang menyatakan bahwa terdapat korelasi yang signifikan antara dukungan orangtua dan tingkat aktivitas fisik anak. Penelitian ini juga membuktikan bahwa orangtua memengaruhi aktivitas fisik anaknya, baik secara langsung maupun tidak langsung. ${ }^{7}$ Penelitian ini telah membuktikan bahwa faktor penentu yang memengaruhi anak melakukan partisipasi dalam aktivitas fisik antara lain usia, jenis kelamin, self-efficacy, dan faktor orangtua (pengetahuan, dukungan, tingkat pendidikan, serta modeling). 7 Orangtua yang memahami bahwa aktivitas fisik dan aktif itu penting akan cenderung memiliki anak lebih aktif dan orangtua aktif secara fisik cenderung lebih terlibat dalam kegiatan fisik anak mereka. ${ }^{7}$

\section{Simpulan}

Aplikasi Sayang ke Buah Hati atau SEHATI berpengaruh dalam meningkatkan pengetahuan ibu tentang aktivitas fisik anak usia sekolah dasar.

\section{Daftar Pustaka}

1. World Health Organization. Fact sheet: physical activity. Updated June 2016 [diunduh 23 Agustus 2016]. Tersedia dari: http://www.who.int/mediacentre/fact sheets/fs385/en.

2. Dobbins M, Husson $\mathrm{H}$, DeCorby $\mathrm{K}$, 
LaRocca RL. School-based physical activity programs for promoting physical activity and fitness in children and adolescents aged 6 to 18. Cochrane Database Syst Rev. 2013;2(2):CDoo7651.

3. Badan Penelitian dan Pengembangan Kesehatan, Kementerian Kesehatan RI. Riset kesehatan dasar (Riskesdas) 2013. Jakarta: Kemenkes RI; 2013.

4. White House Task Force on Childhood Obesity. Report to the president. Solving the problem of childhood obesity within a generation. May 2010 [diunduh 15 September 2016]. Tersedia dari: https:// letsmove.obamawhitehouse.archives.gov/ sites/letsmove.gov/files/TaskForce_on_ Childhood_Obesity_May2010_FullReport. pdf.

5. Vasconcellos F, Seabra A, Katzmarzyk PT, Kraemer-Aguiar LG, Bouskela E, Farinatti P. Physical activity in overweight and obese adolescents: systematic review of the effects on physical fitness components and cardiovascular risk factors. Sports Med. 2014;44(8):1139-52.

6. Council on Sports Medicine and Fitness; Council on School Health. Active healthy living: prevention of childhood obesity through increased physical activity. Pediatrics. 2006;117(5):1834-42.

7. Shaw BS, Shaw I. Determinants of physical activity in children and adolescents: implications for the increasing prevalence of childhood obesity. AJPHERD. 2014;20(Suppl. 2):91-101.

8. Brown T, Summerbell C. Systematic review of school-based interventions that focus on changing dietary intake and physical activity levels to prevent childhood obesity: an update to the obesity guidance produced by the National Institute for Health and Clinical Excellence. Obes Rev. 2009;10(1):110-41.

9. World Health Organization. Global action plan for the prevention and control of noncommunicable disease 2013-2020. Geneva: WHO Press; 2013.

10. Culjak G, Kowalenko N, Spranca M, Tennant C. Internet health promotion and behavior change theory: an integrated model applied to internet interventions to enhance prevention and early detection. Dalam: Bui TX, Sprague RH Jr, penyunting. Proceedings of the 48th Annual Hawaii International Conference on System Sciences. Washington DC; IEEE Computer Society; 2015. hlm. 2970-5.

11. Ho M, Garnett SP, Baur LA, Burrows T, Stewart L, Neve M, dkk. Impact of dietary and exercise interventions on weight change and metabolic outcomes in obese children and adolescents: a systematic review and meta-analysis of randomized trials. JAMA Pediatr. 2013;167(8):759-68.

12. Crespo NC, Corder K, Marshall S, Norman GJ, Patrick K, Sallis JF, dkk. An examination of multilevel factors that may explain gender differences in children's physical activity. J Phys Act Health. 2013;10(7):982-92.

13. Jones RA, Hinkley T, Okely AD, Salmon J. Tracking physical activity and sedentary behavior in childhood: a systematic review. Am J Prev Med. 2013;44(6):651-8.

14. Liese AD, Ma X, Maahs DM, Trilk JL. Physical activity, sedentary behaviors, physical fitness, and their relation to health outcomes in youth with type 1 and type 2 diabetes: a review of the epidemiologic literature. J Sport Health Sci. 2013;2(1):21-38.

15. World Health Organization. Global action plan for the prevention and control of noncommunicable disease 2013-2020. Geneva: WHO Press; 2013.

16. Centers for Disease Control. Make a diference at your school 2013 [diunduh 23 Agustus 2016]. Tersedia dari: http://digitalcommons. hsc.unt.edu/disease/31.

17. Pusat Data dan Informasi Kementerian Kesehatan RI. Kondisi pencapaian program kesehatan anak Indonesia. Jakarta: Kementerian Kesehatan RI; 2014.

18. Kementerian Kesehatan RI. Strategi nasional penerapan pola konsumsi makanan dan aktivitas fisik untuk mencegah penyakit tidak menular. Jakarta: Direktorat Jenderal Bina Gizi dan Kesehatan Ibu dan Anak, Kementerian Kesehatan RI; 2011.

19. Utami RT. Analisis faktor-faktor penyebab obesitas pada siswa Sekolah Dasar Negeri o1 di Kecamatan Kembangan tahun 2014 [diunduh 23 Agustus 2016]. Tersedia dari: http://digilib.esaunggul.ac.id/analisisfaktorfaktor-penyebab-obesitas-pada-siswasekolah-dasar-negeri-o1-dikecamatankembangantahun-2014-3472.html.

20. Pahkala K, Hernelahti M, Heinonen OJ, Raittinen P, Hakanen M, Lagström H, dkk. Body mass index, fitness and physical activity 
from childhood through adolescence. Brit $\mathrm{J}$ Sports Med. 2013;47(2):71-7.

21. Zahro AA. Hubungan tingkat pengetahuan ibu tentang stimulasi verbal dengan perilaku membacakan cerita pada anak di Dusun Petet Desa Tuntang Kecamatan Tuntang Kabupaten Semarang (skripsi). Surakarta: Fakultas Kedokteran, Universitas Sebelas Maret; 2009.

22. Sharma S, Nagar S. Impact of educational intervention on knowledge of mothers regarding child care and nutrition in Himachal Pradesh. J Soc Sci. 2006;12(2):139-42.

23. Penny ME, Creed-Kanashiro HM, Robert RC, Narro MR, Caulfield LE, Black RE. Effectiveness of an educational intervention delivered through the health services to improve nutrition in young children: a cluster-randomised controlled trial. Lancet. 2005;365(9474):1863-72.

24. Notoatmodjo S. Pendidikan dan perilaku kesehatan. Jakarta: Rineka Cipta; 2003.

25. Permatasari D, Kartinah AK. Perbedaan pengaruh pendidikan kesehatan menggunakan leafleat dengan audiovisual terhadap tingkat pengetahuan remaja tentang bahaya minuman keras di Desa Wates Simo Boyolali (skripsi). Surakarta: Fakultas Ilmu Kesehatan, Universitas Muhammadiyah Surakarta; 2013.

26. Kapti RE, Rustina Y, Widyatuti W. Efektifitas audiovisual sebagai media penyuluhan kesehatan terhadap peningkatan pengetahuan dan sikap ibu dalam tatalaksana balita dengan diare di dua rumah sakit Kota Malang. JIK. 2013;1(1):53-60.

27. O'Day DH. The value of animations in biology teaching: a study of long-term memory retention. CBE Life Sci Educ. 2007;6(3):217-23.

28. Balazinski M, Przybylo A. Teaching manufacturing processes using computer animation. J Manufact Syst. 2005;24(3):237-43.

29. Aksoy G. Effect of computer animation technique on students' comprehension of the "solar system and beyond" unit in the science and technology course. MIJE. 2013;3(1):40-6.

30. Gustafson SL, Rhodes RE. Parental correlates of physical activity in children and early adolescents. Sports Med. 2006;36(1):79-97. 